\title{
Simulation and Arduino Hardware Implementation of DC Motor Control Using Sliding Mode Controller
}

\author{
Alfian Ma'arif ${ }^{1 *}$, Abdullah Çakan ${ }^{2}$ \\ ${ }^{1}$ Universitas Ahmad Dahlan, Yogyakarta, Indonesia \\ ${ }^{2}$ Konya Technical University, Konya, Turkey \\ Email: ${ }^{1}$ alfianmaarif@ee.uad.ac.id \\ *Corresponding Author
}

\begin{abstract}
The research proposed an alternative controller to control the Direct Current (DC) Motor using a sliding mode controller (SMC) in Matlab Simulink simulation and Arduino hardware implementation. The proposed controller, SMC, was designed using the system model (equivalent control) and Lyapunov control design (also to prove the stability). The sliding mode controller had a better response than PID Controller, with no overshoot response in the simulation result. In the Arduino hardware implementation result, the augmented system could reach the reference but has an oscillation and chattering effect in the control signal. The chattering could be reduced by modifying the switching control. Comparing with PID, SMC had a better response with no overshoot. Thus, the SMC could be used as an alternative controller for the DC Motor.
\end{abstract}

Keywords-DC Motor, Sliding Mode Controller, Arduino, PID Control, Matlab

\section{INTRODUCTION}

Direct Current (DC) motors play an important role in vehicles [1][2], robotics [3][4][5], aircraft [6], and industrial [7][8][9]. The common controller used in DC motor is Proportional Integral Derivative (PID) Controller [10]. The main weakness of the PID controller is inconsistent performance [11][12]. The parameter of the controller only has good performance in one set point. In other set points, the given response would be different [13].

The other controller is the Fuzzy Logic Controller (FLC) $[14][15][16][17][18][19]$. It is not easy to be designed, especially if it has many inputs. It requires experience, as in experimental data, to be able to design a suitable controller. It also needs more memory if it has many rules. Thus, we need an alternative controller for DC Motor. Another controller is the state feedback controller [20][21][22]. However, the controller needs all of the state must be measurable in hardware implementation. Thus it cannot work only using one sensor.

The alternative controller for DC Motor is the Sliding Mode Controller (SMC) that has the advantage of avoiding uncertainties and disturbance [23][24]. It is similar to the Variable Structure System (VSS) and is included in the nonlinear controller [25]. It has been applied to many systems, such as Magnetic Levitation System [26][27], Buck Converter [28][29], Quadcopter [30][31], Quadrotor [32], Unmanned Surface Vehicle [33], DC/DC Converters [34] and robot Manipulator [35][36][37]. Nevertheless, all mentioned researches were limited to simulation purpose only.

The simulation about sliding mode controller had been done before [38][39][40][41][42]. They resulted in a good performance, but we need the hardware implementation to observe more. This research would do not only the simulation but also the hardware implementation. For a simple implementation, it would use the Arduino microcontroller. The advantage of using the Arduino is low-cost [43][44][45], small [46], and has many applications [47][48][49][50]. Thus, it will good for the education purpose [51] and the hardware implementation.

The paper will be structured as follows. The first section of the paper is the introduction. Next, the second section is the modeling of DC Motor. Then, the next section is the sliding mode controller design. The following section is the result and discussion that consist of numerical simulation and hardware implementation. The last section is the conclusions and the future work.

\section{MODEL OF DC MOTOR}

The DC Motor diagram is shown in Figure 1. The variable $v_{D C}$ is the DC power supply, $v_{E m f}$ is the back electromotive force voltage, $R$ is the armature resistance, $L$ is the armature inductance, $f_{k}$ is the friction torque, $J$ is the inertia, $\omega$ is the angular speed, $T$ is the motor torque, $i$ is the armature current.

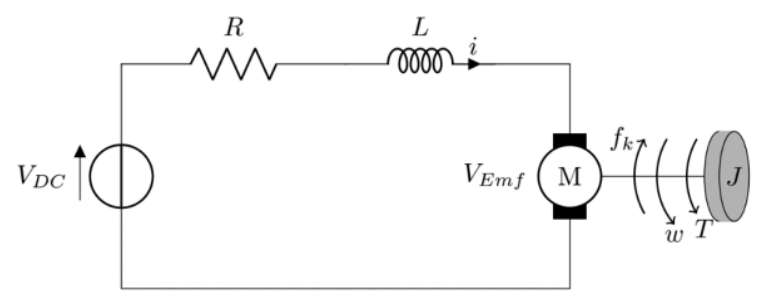

Fig. 1. DC Motor Diagram

The equations with Kirchhoff voltage law analysis is obtained as 


$$
R i+L \frac{d i}{d t}=v-K_{e} \omega
$$

where variable $K_{e}$ is the electromotive force constant.

The equation with Newton second law for rotation is obtained as

$$
J \dot{\omega}+b \omega=K_{t} i
$$

where $K_{t}$ is the motor torque constant, and $b$ is the motor friction constant.

After using the mathematical processing with (1) and (2), we obtained

$$
\begin{gathered}
L \frac{d i}{d t}=-R i-K_{e} \omega+v \\
J \dot{\omega}=-b \omega+K_{t} i
\end{gathered}
$$

Define the state space variables and the control signal variable as

$$
\begin{aligned}
& x_{1}=\omega \\
& x_{2}=i \\
& u=v
\end{aligned}
$$

Then, we obtained the derivation of the state space variable as

$$
\begin{gathered}
\dot{x}_{1}=\dot{\omega}=\frac{d \theta}{d t}=-\frac{b}{J} \omega+\frac{K_{t}}{J} i \\
\dot{x}_{2}=\dot{i}=\frac{d i}{d t}=-\frac{K_{e}}{L} \omega-\frac{R}{L} i+\frac{1}{L} u
\end{gathered}
$$

Then, we used the substitution to obtain

$$
\begin{gathered}
\dot{x}_{1}=-\frac{b}{J} x_{1}+\frac{K_{t}}{J} x_{2} \\
\dot{x}_{2}=-\frac{K_{e}}{L} x_{1}-\frac{R}{L} x_{2}+\frac{1}{L} u
\end{gathered}
$$

The state-space model is

$$
\begin{gathered}
\dot{x}=A x+B u \\
y=C x
\end{gathered}
$$

Where

$$
x=\left[\begin{array}{l}
x_{1} \\
x_{2}
\end{array}\right] \quad A=\left[\begin{array}{cc}
-\frac{b}{J} & \frac{K_{t}}{J} \\
-\frac{K_{e}}{L} & -\frac{R}{L}
\end{array}\right] \quad B=\left[\begin{array}{l}
0 \\
\frac{1}{L}
\end{array}\right] \quad C=\left[\begin{array}{ll}
1 & 0
\end{array}\right]
$$

The parameter value of DC Motor is shown in Table I. The parameter was used in the simulation and controller design.

The state-space model in (12) and (13) using the parameter from Table 1 was

$$
\begin{gathered}
\dot{x}=\left[\begin{array}{cc}
-5.5 & 37.5 \\
-0.01852 & -0.1481
\end{array}\right] x+\left[\begin{array}{c}
0 \\
0.3704
\end{array}\right] u \\
y=\left[\begin{array}{ll}
1 & 0
\end{array}\right] x
\end{gathered}
$$

Based on the state-space model, the transfer function model can be obtained as (it can use Matlab function ss2tf)

$$
\omega(s)=\frac{13.89}{s^{2}+5.648 s+1.509} v(s)
$$

TABLE I. DC MOTOR PARAMETER VALUe [52]

\begin{tabular}{|c|c|}
\hline Parameter & Value \\
\hline$R$ & 0.4 \\
\hline$L$ & 2.7 \\
\hline$J$ & 0.0004 \\
\hline$K_{b}$ & 0.0022 \\
\hline$K_{t}$ & 0.015 \\
\hline$K_{e}$ & 0.05 \\
\hline
\end{tabular}

\section{Sliding Mode CONTROLler DeSIGN}

The sliding mode controller needs the model in the state space controllable form. Thus, the transfer function model in (16) can be written time domain as

$$
\ddot{\omega}+5.648 \dot{\omega}+1.509 \omega=13.89 v
$$

Then, we define the state space variable as

$$
\begin{aligned}
& x_{1}=\omega \\
& x_{2}=\dot{\omega} \\
& u=v
\end{aligned}
$$

We obtain the state-space model in the controllable canonical form as

$$
\begin{gathered}
\dot{x}_{1}=x_{2} \\
\dot{x}_{2}=-5.648 x_{2}-1.509 x_{1}+13.89 u
\end{gathered}
$$

The first step to designing the sliding mode controller was designing the sliding mode function as

$$
s=c e+\dot{e}
$$


Where variable $e$ is the tracking error and variable $c$ must satisfy the Hurwitz condition $(c>0)$.

The tracking error and the derivation are

$$
\begin{aligned}
& e=\omega_{d}-\omega \\
& \dot{e}=\dot{\omega}_{d}-\dot{\omega} \\
& \ddot{e}=\ddot{\omega}_{d}-\ddot{\omega}
\end{aligned}
$$

where variable $\omega_{d}$ is the reference signal, and $\omega$ is the actual angular speed.

Define the Lyapunov function as

$$
V=\frac{1}{2} s^{2}
$$

To guarantee the stability condition, the derivation of the Lyapunov function in (27) must be $\dot{V}<0$ as

$$
s \dot{S}<0
$$

The derivation of the sliding mode function is

$$
\begin{gathered}
\dot{s}=c \dot{e}+\ddot{e} \\
=c \dot{e}+\ddot{\omega}_{d}-\ddot{\omega} \\
=c \dot{e}+\ddot{\omega}_{d}+5.648 \dot{\omega}+1.509 \omega-13.89 u
\end{gathered}
$$

Thus the derivation of the Lyapunov function $\dot{V}$ is

$$
s \dot{s}=s\left(c \dot{e}+\ddot{\omega}_{d}+5.648 \dot{\omega}+1.509 \omega-13.89 u\right)
$$

To satisfy the condition $s \dot{S}<0$, the sliding mode controller is designed as

$$
u=\frac{1}{13.89}\left(1.509 \omega+5.648 \dot{\omega}+\ddot{\omega}_{d}+c \dot{e}\right.
$$

Where

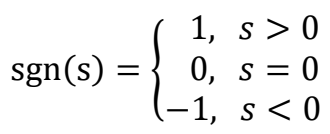

Substitute (33) to (28), then we get

$$
s \dot{s}=-K \operatorname{sgn}(\mathrm{s})<0
$$

\section{RESUlTS AND DISCUSSION}

The section will be divided into two. The first part is the numerical simulation using Matlab Software. Then, the second part is the hardware implementation using the Arduino microcontroller.

\section{A. Numerical Simulation}

In the section, the simulation used the Simulink Matlab Software. The Simulink setup is shown in Figure 2. The SMC control signal is in (33).

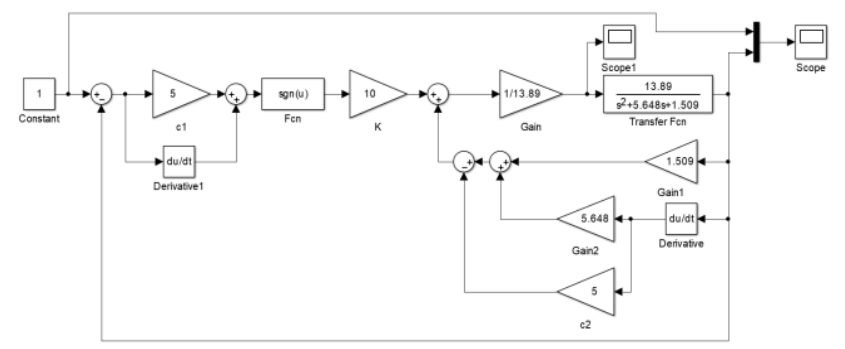

Fig. 2. Simulation Setup in Simulink Matlab

Comparing system response with PID, the result for the step reference signal is shown in Figure 3. The detailed system response is shown in Table II. It can be seen that the SMC response did not have an overshoot. Meanwhile, the PID response had a $22.48 \%$ overshoot. Thus, the SMC response was better than the PID Controller.

TABLE II. SYSTEM RESPONSE PERFORMANCE

\begin{tabular}{|l|c|c|c|}
\hline \multirow{2}{*}{ Controller } & \multicolumn{3}{|c|}{ System Response Performance } \\
\cline { 2 - 4 } & Rise Time & Settling Time & Overshoot \\
\hline SMC & 0.6070 & 1.0899 & 0 \\
\hline PID & 0.1830 & 1.0014 & 22.4793 \\
\hline
\end{tabular}

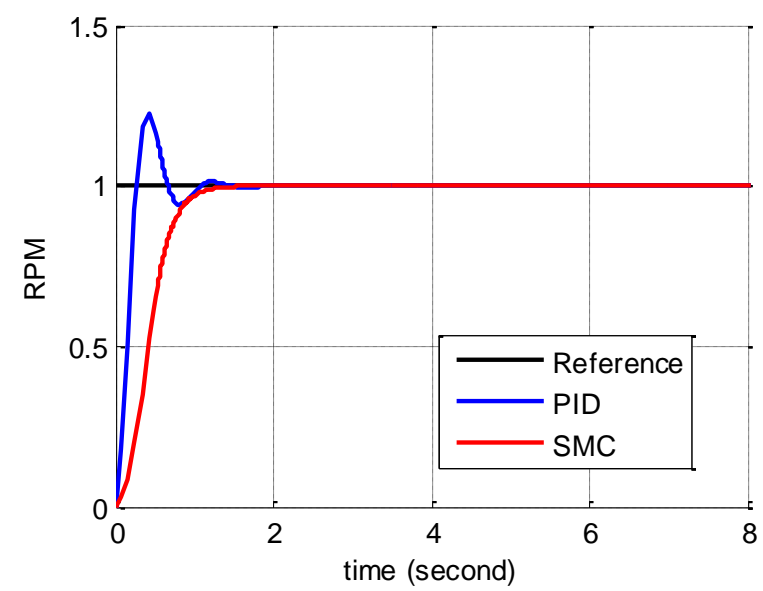

Fig. 3. Response system

\section{B. Arduino Hardware Implementation}

In this section, the hardware implementation would be conducted using Arduino, DC Motor JGA25, Driver Motor L298, Encoder, and Current Sensor INA219. The device setup is shown in Figure 4.

The result is shown in Figure 5. The SMC control signal is shown in Figure 6. It can be seen that the system could reach the reference but had an oscillation. The SMC control signal had a chattering effect. 
The sliding mode controller was modified to reduce the chattering effect, as

$$
\begin{gathered}
u=\frac{1}{13.89}\left(1.509 \omega+5.648 \dot{\omega}+\ddot{\omega}_{d}+c \dot{e}\right. \\
\left.+K \frac{\mathrm{s}}{|s|+\delta}\right)
\end{gathered}
$$

Where the parameter $\delta$ is the scalar tuning parameter to reduce the chattering effect.

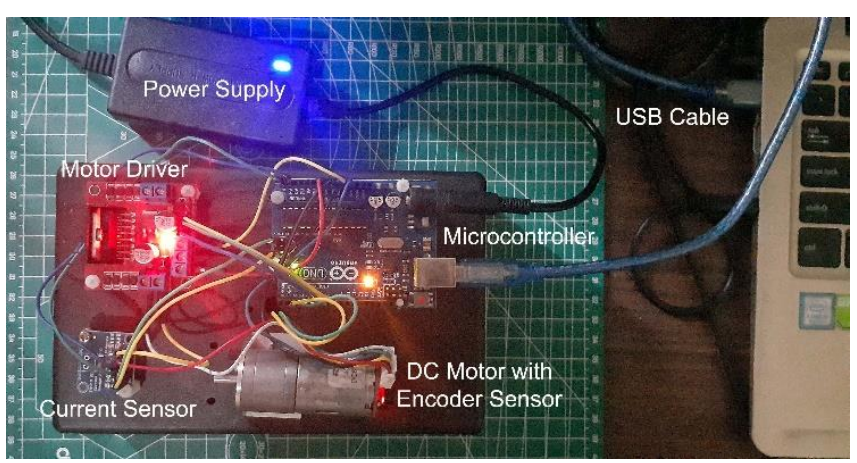

Fig. 4. DC Motor Hardware Setup

The system's responses and control signal using modified switching function in (36) is shown in Figure 7 and Figure 8. It can be shown that the chattering effect was reduced, and the system response was better than before.

The subsequent examination was a comparison between the SMC and PID controller. The result is shown in Figure 9. It can be seen that SMC 1 and SMC 2 did not have any overshoot. Meanwhile, the PID control had an overshoot. The PID had a small oscillation than the SMC.

\section{CONCLUSIONS AND FUTURE WORK}

The paper proposed DC Motor control using the sliding mode controller in simulation and hardware implementation. Based on the simulation, the SMC had a better response than PID Controller. Meanwhile, in hardware implementation, SMC had oscillation to follow the reference. Thus, the SMC could be implemented in the hardware system but still need improvement to reduce the oscillation.

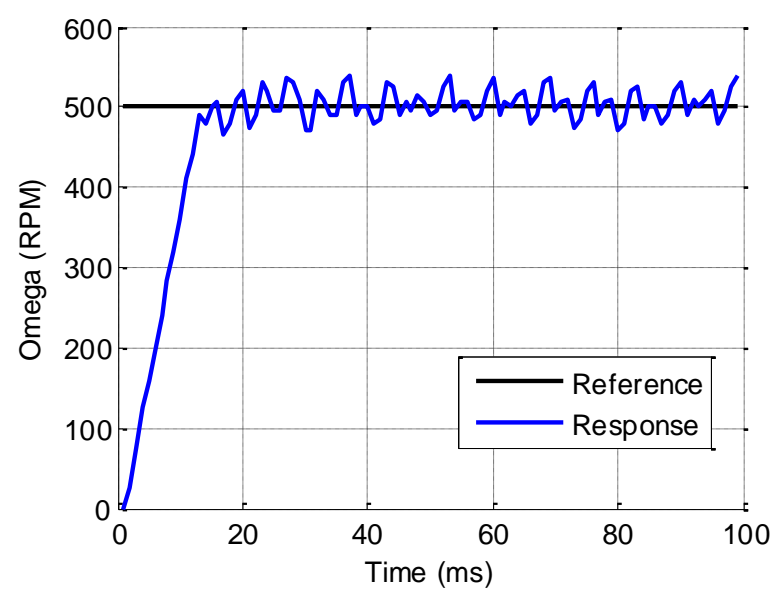

Fig. 5. SMC System Response

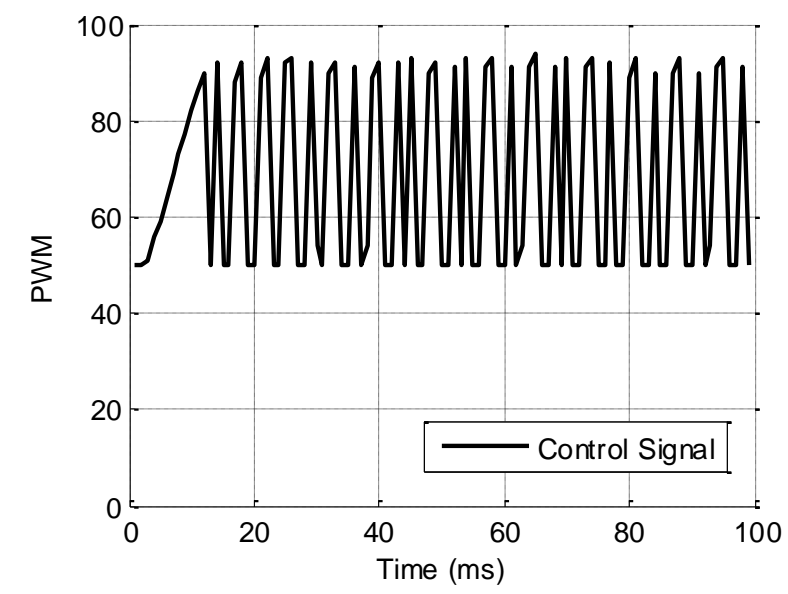

Fig. 6. SMC Control Signal

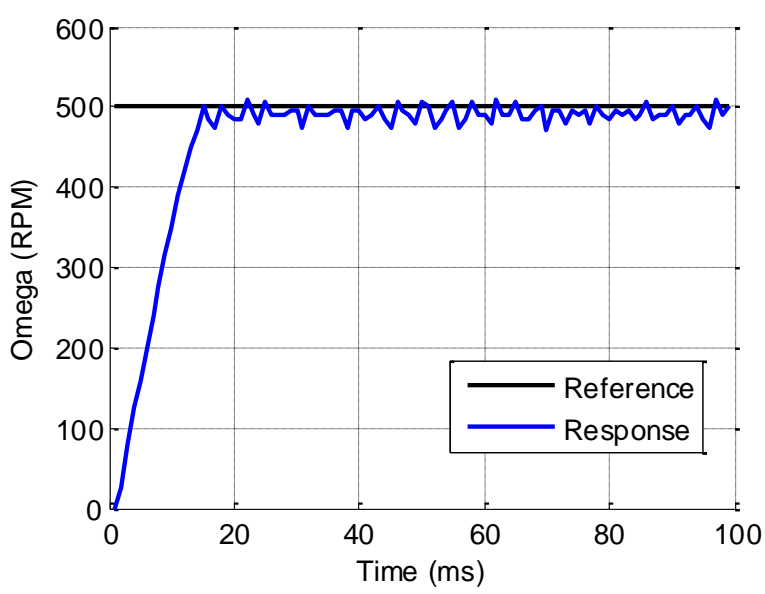

Fig. 7. SMC System Response

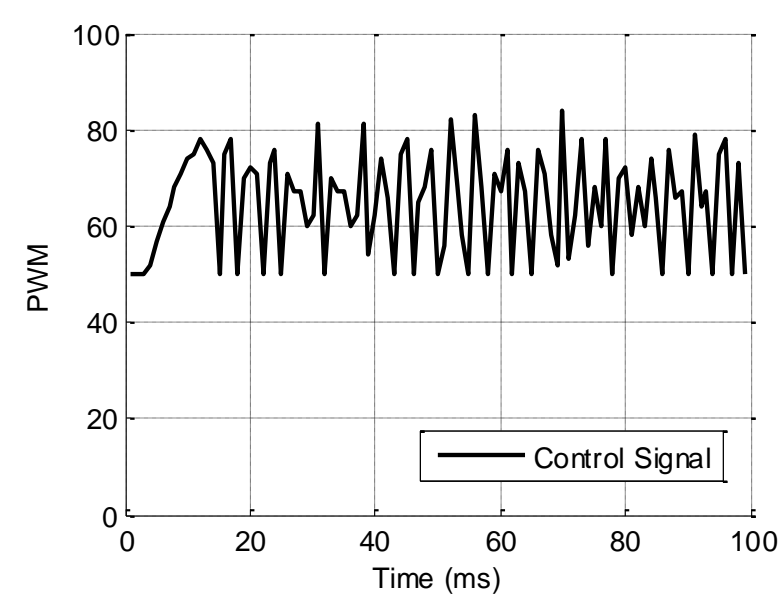

Fig. 8. SMC Control Signal 


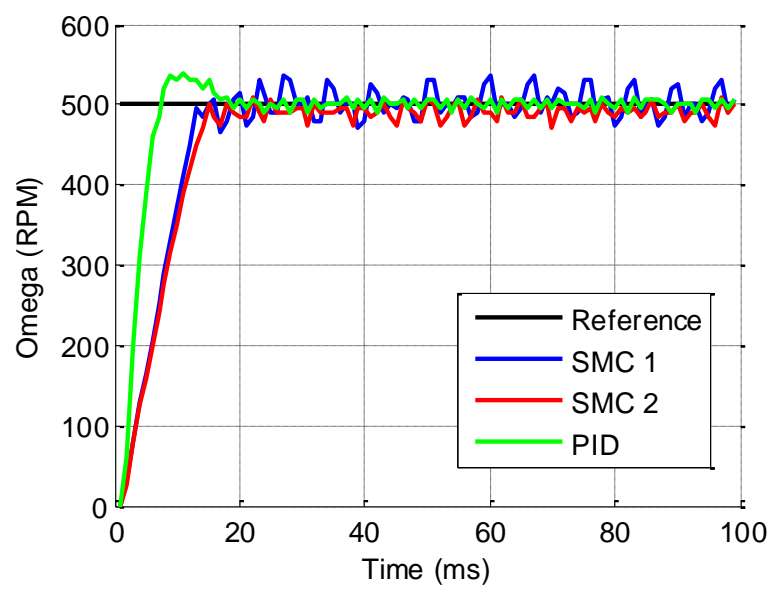

Fig. 9. Comparing SMC with PID

\section{REFERENCES}

[1] M. A. Hassanin, F. E. Abdel-Kader, S. I. Amer, and A. E. AbuMoubarka, "Operation of Brushless DC Motor to Drive the Electric Vehicle," in 2018 20th International Middle East Power Systems Conference, MEPCON 2018 - Proceedings, 2019, pp. 500-503.

[2] P. Vishnu Sidharthan and Y. Kashyap, "Brushless DC hub motor drive control for electric vehicle applications," in 2020 1st International Conference on Power, Control and Computing Technologies, ICPC2T 2020, 2020, pp. 448-453.

[3] J. Meng, A. Liu, Y. Yang, Z. Wu, and Q. Xu, "Two-Wheeled Robot Platform Based on PID Control," in Proceedings - 2018 5th International Conference on Information Science and Control Engineering, ICISCE 2018, 2019, pp. 1011-1014.

[4] K. Sharma and D. K. Palwalia, "A modified PID control with adaptive fuzzy controller applied to DC motor," in IEEE International Conference on Information, Communication, Instrumentation and Control, ICICIC 2017, 2018, vol. 2018-Janua, pp. 1-6.

[5] R. R. Carmona, H. G. Sung, Y. S. Kim, and H. A. Vazquez, "Stable PID Control for Mobile Robots," in 2018 15th International Conference on Control, Automation, Robotics and Vision, ICARCV 2018, 2018, pp. 1891-1896.

[6] M. Ahmed, N. M. Tahir, A. Y. Zimit, M. Idi, K. A. Abubakar, and S. A. Jalo, "Improved PID Controller for DC Motor Control," IOP Conference Series: Materials Science and Engineering, vol. 1052, no. 1, p. 012058, Jan. 2021.

[7] V. Yadav and V. K. Tayal, "Optimal Controller Design for a DC Motor using PID Tuner," in 2018 International Conference on Power Energy, Environment and Intelligent Control, PEEIC 2018, 2019, pp. 442-445.

[8] S. A. Bhatti, S. A. Malik, and A. Daraz, "Comparison of P-I and I-P controller by using Ziegler-Nichols tuning method for speed control of DC motor," in 2016 International Conference on Intelligent Systems Engineering, ICISE 2016, 2016, pp. 330-334.

[9] I. Khanam and G. Parmar, "Application of SFS algorithm in control of DC motor and comparative analysis," in 2017 4th IEEE Uttar Pradesh Section International Conference on Electrical, Computer and Electronics, UPCON 2017, 2017, vol. 2018-Janua, pp. 256-261.

[10] N. M. A. Mohamed, A. A. A. Abdalaziz, A. A. Ahmed, and A. A. A. Ahmed, "Implementation of a PID control system on microcontroller (DC motor case study)," in Proceedings - 2017 International Conference on Communication, Control, Computing and Electronics Engineering, ICCCCEE 2017, 2017.

[11] R. V. Jain, M. V. Aware, and A. S. Junghare, "Tuning of Fractional Order PID controller using particle swarm optimization technique for DC motor speed control," in 1st IEEE International Conference on Power Electronics, Intelligent Control and Energy Systems, ICPEICES 2016, 2017.

[12] I. S. Okoro and C. O. Enwerem, "Robust control of a DC motor," Heliyon, vol. 6, no. 12, Dec. 2020.

[13] K. Boudaraia, H. Mahmoudi, M. Abbou, and M. Hilal, "DC motor position control of a solar tracking system using second order sliding mode," in International Conference on Multimedia Computing and Systems -Proceedings, 2017, vol. 0, pp. 594-598.
[14] N. L. Ismail, K. A. Zakaria, N. S. M. Nazar, M. Syaripuddin, A. S. N. Mokhtar, and S. Thanakodi, "DC motor speed control using fuzzy logic controller," in AIP Conference Proceedings, 2018, vol. 1930, no. 1, p. 020026.

[15] Y. A. Almatheel and A. Abdelrahman, "Speed control of DC motor using Fuzzy Logic Controller," in Proceedings - 2017 International Conference on Communication, Control, Computing and Electronics Engineering, ICCCCEE 2017, 2017.

[16] K. Sreeram, "Design of Fuzzy Logic Controller for Speed Control of Sensorless BLDC Motor Drive," in 2018 International Conference on Control, Power, Communication and Computing Technologies, ICCPCCT 2018, 2018, pp. 18-24.

[17] A. Mousmi, Y. Houm, and A. Abbou, "Implementation of a fuzzy logic controller for a BLDC motor," in 3rd Renewable Energies, Power Systems and Green Inclusive Economy, REPS and GIE 2018, 2018.

[18] D. Perdukova, P. Fedor, and V. Fedak, "A fuzzy approach to optimal DC motor controller design," in International Conference on Electical Drives and Power Electronics, 2019, vol. 2019-Septe, pp. 48-53.

[19] B. Ananthababu, C. Ganesh, and C. V. Pavithra, "Fuzzy based speed control of BLDC motor with bidirectional DC-DC converter," in Proceedings of 2016 Online International Conference on Green Engineering and Technologies, IC-GET 2016, 2017.

[20] G. Liu and X. Zhang, "State Feedback Control and Applied to PV Systems Under Improved MPPT Control," in 2018 IEEE 4th International Conference on Control Science and Systems Engineering, ICCSSE 2018, 2018, pp. 145-149.

[21] M. Ahmad, A. Khan, M. A. Raza, and S. Ullah, "A study of state feedback controllers for pole placement," in 5th International MultiTopic ICT Conference: Technologies For Future Generations, IMTIC 2018 - Proceedings, 2018.

[22] D. M. Soares, H. A. M. Calil, and R. M. Stephan, "Cascade Control vs Full-State Feedback," in 2019 IEEE 15th Brazilian Power Electronics Conference and 5th IEEE Southern Power Electronics Conference, COBEP/SPEC 2019, 2019.

[23] J. Yang, S. Li, and X. Yu, "Sliding-mode control for systems with mismatched uncertainties via a disturbance observer," IEEE Transactions on Industrial Electronics, vol. 60, no. 1, pp. 160-169, 2013.

[24] M. Zhou, D. Mao, M. Zhang, L. Guo, and M. Gong, “A Hybrid Control with PID-Improved Sliding Mode for Flat-Top of Missile Electromechanical Actuator Systems," Sensors, vol. 18, no. 12, p. 4449, Dec. 2018.

[25] E. S. Sinekli and R. Coban, "Dynamic integral sliding mode control of an electromechanical system," in 2017 International Conference on Mechanical, System and Control Engineering, ICMSC 2017, 2017, pp. 160-164.

[26] R. Uswarman, S. Istiqphara, and D. H. Tri Nugroho, "Sliding Mode Control with Gain Scheduled for Magnetic Levitation System," Jurnal Ilmiah Teknik Elektro Komputer dan Informatika, vol. 5, no. 1, pp. 3643, 2019.

[27] H. M. M. Adil, S. Ahmed, and I. Ahmad, "Control of MagLev System Using Supertwisting and Integral Backstepping Sliding Mode Algorithm," IEEE Access, vol. 8, pp. 51352-51362, 2020.

[28] K. G. Shankar, D. Jena, and R. Reddivari, "Comparative Overview of Internal Model Control Based PID, State Feedback Integral, and Sliding Mode Controllers for Buck Converter," in 2019 IEEE International Conference on Distributed Computing, VLSI, Electrical Circuits and Robotics, DISCOVER 2019 - Proceedings, 2019.

[29] L. Du, P. Huang, and W. Tong, "Research on full-order sliding mode control method for buck converter," in 2019 IEEE 3rd International Conference on Electronic Information Technology and Computer Engineering, EITCE 2019, 2019, pp. 1171-1175.

[30] R. Uswarman, S. Istiqphara, R. A. Yunmar, and A. Z. Rakhman, "Robust Control of a Quadcopter Flying Via Sliding Mode," Journal of Science and Application Technology, vol. 2, no. 1, pp. 135-143, Jun. 2019.

[31] R. Uswarman and S. Istiqphara, "Perancangan Sistem Kendali Quadcopter Menggunakan Modified Sliding Mode Control," Jurnal Nasional Teknik Elektro dan Teknologi Informasi (JNTETI), vol. 8, no. 3, p. 273, Aug. 2019.

[32] D. J. Almakhles, "Robust Backstepping Sliding Mode Control for a Quadrotor Trajectory Tracking Application," IEEE Access, vol. 8, pp. $5515-5525,2020$. 
[33] C. Xiu and P. Guo, "Global Terminal Sliding Mode Control with the Quick Reaching Law and Its Application," IEEE Access, vol. 6, pp. 49793-49800, Sep. 2018.

[34] S. Lee, Y. C. Jeung, and D. C. Lee, "Voltage balancing control of IPOS modular dual active bridge DC/DC converters based on hierarchical sliding mode control," IEEE Access, vol. 7, pp. 9989-9997, 2019.

[35] W. Boukadida, R. Bkekri, A. Benamor, and H. Messaoud, "Trajectory tracking of robotic manipulators using optimal sliding mode control," in 2017 International Conference on Control, Automation and Diagnosis, ICCAD 2017, 2017, pp. 545-550.

[36] S. Ilgen, A. Durdu, E. Gulbahce, and A. Cakan, "Sliding mode control of a two-link robot manipulator using adams matlab software," in 2018 6th International Conference on Control Engineering and Information Technology, CEIT 2018, 2018.

[37] T. N. Truong, A. T. Vo, and H. J. Kang, “A Backstepping Global Fast Terminal Sliding Mode Control for Trajectory Tracking Control of Industrial Robotic Manipulators," IEEE Access, 2021.

[38] H. Maghfiroh, A. Sujono, C. Hermanu, and B. Apribowo, "Basic Tutorial on Sliding Mode Control in Speed Control of DC-motor," Apr. 2020.

[39] B. A. Reddy and D. Sowjanya, "Control of D.C Motor Using Sliding Mode Control under Disturbance Conditions," in Proceedings of the 3 rd International Conference on Inventive Systems and Control, ICISC 2019, 2019, pp. 32-36.

[40] R. Coban, "Backstepping integral sliding mode control of an electromechanical system," Automatika, vol. 58, no. 3, pp. 266-272, 2017.

[41] S. A. Al-Samarraie and M. Hussein Mishary Me, "A Chattering Free Sliding Mode Observer with Application to DC Motor Speed Control," in 2018 3rd Scientific Conference of Electrical Engineering, SCEE 2018, 2018, pp. 259-264.

[42] S. Rakhonde and V. Kulkarni, "Sliding mode controller (SMC) governed speed control of DC motor," in 20183 rd IEEE International Conference on Recent Trends in Electronics, Information and Communication Technology, RTEICT 2018 - Proceedings, 2018, pp. 1657-1662.

[43] Z. Tir, O. Malik, M. A. Hamida, H. Cherif, Y. Bekakra, and A. Kadrine, "Implementation of a fuzzy logic speed controller for a permanent magnet dc motor using a low-cost Arduino platform," in 2017 th International Conference on Electrical Engineering - Boumerdes, ICEE-B 2017, 2017, vol. 2017-Janua, pp. 1-4.
[44] A. A. C. Carcamo, M. G. M. Reyes, and S. M. S. Urbina, "Low cost Pulse Oximeter using Arduino," in IEEE CHILEAN Conference on Electrical, Electronics Engineering, Information and Communication Technologies, CHILECON 2019, 2019.

[45] M. S. Kumar, T. R. Chandra, D. P. Kumar, and M. S. Manikandan, "Monitoring moisture of soil using low cost homemade Soil moisture sensor and Arduino UNO," in ICACCS 2016 - 3rd International Conference on Advanced Computing and Communication Systems: Bringing to the Table, Futuristic Technologies from Arround the Globe, 2016.

[46] G. Gasparesc, "PID control of a DC motor using Labview Interface for Embedded Platforms," in 2016 12th International Symposium on Electronics and Telecommunications, ISETC 2016 - Conference Proceedings, 2016, pp. 145-148.

[47] S. Gunputh, A. P. Murdan, and V. Oree, "Design and implementation of a low-cost Arduino-based smart home system," in 2017 9th IEEE International Conference on Communication Software and Networks, ICCSN 2017, 2017, vol. 2017-Janua, pp. 1491-1495.

[48] J. Sheng, "Real Time DC Water Tank Level Control using Arduino Mega 2560," in IEEE International Symposium on Industrial Electronics, 2019, vol. 2019-June, pp. 635-640.

[49] S. Dhingra, R. B. Madda, A. H. Gandomi, R. Patan, and M. Daneshmand, "Internet of things mobile-air pollution monitoring system (IoT-Mobair)," IEEE Internet of Things Journal, vol. 6, no. 3, pp. 5577-5584, Jun. 2019.

[50] M. Lobur, D. Korpyljov, N. Jaworski, M. Iwaniec, and U. Marikutsa, "Arduino Based Ambient Air Pollution Sensing System," in 2020 IEEE 16th International Conference on the Perspective Technologies and Methods in MEMS Design, MEMSTECH 2020 - Proceedings, 2020, pp. 32-35.

[51] J. H. Li, "Control system laboratory with arduino," in Proceedings 2018 International Symposium on Computer, Consumer and Control, IS3C 2018, 2019, pp. 181-184.

[52] B. Hekimoglu, "Optimal Tuning of Fractional Order PID Controller for DC Motor Speed Control via Chaotic Atom Search Optimization Algorithm," IEEE Access, vol. 7, pp. 38100-38114, 2019. 